\title{
Relationship between Interprofessional Communication and Sharing Information and Nurses' Burnout and Work Autonomy
}

\author{
Reem Mabrouk Abd El Rahman. \\ Lecturer, Nursing Administration Department, Faculty of Nursing - University of Damanhour.
}

\begin{abstract}
Interprofessional communication can positively improve clinical outcomes. Aim: to examine the relationship between interprofessional communication and sharing information and nurses' burnout and work autonomy. Methods: Design: cross-sectional correlational. Sampling: all physicians and nurses working in critical care units at Damanhour National Medical Institute, Egypt ( $\mathrm{N}=167)$. Tools: self-administered questionnaires composed of four parts, namely: Communication and Sharing Information (CSI) scale; Maslach Burnout Inventory-Human Services Scale (MBI-HSS); Global Work Autonomy Scale (GWA); and a demographic data sheet. Results: the findings showed that sharing of medical information and nurses-physicians communication were the highest dimensions. High mean of emotional exhaustion; depersonalization; and personal accomplishment dimensions of burnout; as well as total work autonomy. Significant differences were found between age and interprofessional communication and sharing information and both burnout dimensions (emotional exhaustion) and (depersonalization). No significant differences were found between all demographic characteristics and both nurses' burnout (personal accomplishment) and total work autonomy. An intermediate positive correlation was found between total communication and sharing information and burnout dimensions: emotional exhaustion and depersonalization and total work autonomy. Conclusion: total communication and sharing information are positively correlated to both burnout subscales: emotional exhaustion and depersonalization; and total work autonomy. However, total communication and sharing information and burnout subscale (personal accomplishment) are not correlated. Recommendations: strategies that foster patient-centered communication; and development of policies to equalize power dynamics; and enhance teamwork should be implemented.
\end{abstract}

\section{Keywords: Interprofessional Communication, Sharing Information, Nurses' Burnout \& Work} Autonomy.

\section{Introduction}

In recent years, much attention has been paid to quality and safety of hospital care (Anthoine et al., 2014). The intensive care unit (ICU) represents an important setting for improving communication about care because death is common and because patients are at high risk for both mortality and long-term morbidity (Hough \& Curtis, 2005). The ICU is an important setting for improving communication about the goals of care since the current quality of communication is often poor (Wall et al., 2007). Nurses and physicians make up the largest group of healthcare providers, and both daily confront complex problems with no easy solutions (Keenan et al., 1998). Nurses do not work in isolation; rather they collaborate and interact with other members of the healthcare team to provide quality patient care (Doran et al., 2002). However, communication between the professions does not flow as it should (Greenfield, 1999). Failures in communication among the members of the interdisciplinary team have been proven to create life-threatening situations for patients; which stems from the belief of physicians that the nurse and physician are not equals and do not play the same role; that role being to provide safe, effective and efficient treatment to alleviate pain and create a sense of healing (Institute Of Medicine (IOM), 2011). Although nursing is typically characterized as caring and medicine as curing, both are essentially healing disciplines combining art, science and craft and comprising caring, treatment and curative functions both of these professions cannot operate in isolation or a specific sphere (Thompson \& Stewart, 2007).

These characteristics necessitate a team approach to care delivery that encourages effective interprofessional communication (Rose, 2011). Communication between nurses and physicians is a key factor in ICU outcomes (Baggs et al., 1999). ICUs in which there is poor collaborative communication among nurses and physicians, ineffective leadership, poor nurse staffing, less technological availability, and greater diagnostic diversity, patient risk adjusted mortality and length of stay is increased as much as 1.8 -fold; significantly higher nursing turnover, lower perceived ability to meet family needs, and lower perceived technical quality of care also exist in these units (Baggs et al., 1999). The Joint Commission (2006) found that a 
lack of communication among healthcare team members was responsible for as many as $70 \%$ of adverse events. Ineffective communication was cited as the primary root cause of sentinel events within healthcare facilities across the United States (Joint Commission, 2012). Given that $20 \%$ of deaths in the U.S. occur in or shortly after a stay in the ICU and that the quality of decision-making and communication for critically ill patients is variable and often poor (Curtis \& Vincent, 2010). Quality of care depends on an organization that ensures the continuity of information and interprofessional communication (Krogstad et al., 2004). Improving the professional communication can guarantee the quality of professional services to the patients (Azimi et al., 2011).

Interprofessional communication has beneficial effect on medication error and the improvement of behavioral disturbances among nurses (Scott et al., 2008). It is described as working together between nursing and medicine, sharing in decision making around health and social issues, to formulate and carry out plans for patient care and solving patients' problems (Bridges, 2011). Interprofessional communication has been defined as "the process of developing and maintaining a partnership between a team of health professionals and a client in a participatory, collaborative and coordinated approach to share decision-making around health and social issues" (Orchard et al., 2005). More recently, professional communication in clinical settings is viewed as healthcare professionals' relationships with each other as well as their exchange of knowledge and skill for making wise clinical decisions about patient care (Kenaszchuk et al., 2010). It is considered as the heart of all interactions (Chitty $\&$ Black, 2007). Dimensions of nurse-physician interprofessional communication are: sharing of medical information between healthcare professionals; communication between physicians; and communication between nurses and nurse assistants (Anthoine et al., 2014).

Nurses and physicians communication can positively improve clinical outcomes such as patient death rate; and can decrease institutional costs (Tyson \& Pongruengphant, 2004). In addition, higher nurse burnout has been found to be related to poor nursephysician work relationships (Rafferty et al., 2001). ICUs are characterized by a high level of workrelated stress, a factor known to increase the risk of burnout (Bakker et al., 2005), which is characterized by negative emotional, psychological and physical reactions to work-related stress (Raj, 2006). Burnout is associated with decreased wellbeing among nursing staff (Aiken et al., 2002), decreased quality of care (Arnedt et al., 2005), all of which have particularly devastating consequences in the ICU. Burnout is a psychological concept often used as a response to prolonged emotional and job related interpersonal stressors, usually in the work context (Myhren et al., 2013). It has three key dimensions: emotional exhaustion which measures feelings of being emotionally overextended, exhausted by one's work and diminution of energy; depersonalization (or cynicism) which measures an unfeeling and impersonal response toward recipients of one's service, care treatment, or instruction by actively ignoring the qualities that make them unique and engaging people; and a lack of personal accomplishment which indicates negative evaluation of one's work related to feelings of reduced competence (Maslach et al., 2003).

Characteristics of the work (e.g. workload, social support, and autonomy) may be associated with psychological reactions like burnout in staff (Merlani et al., 2011). Nursing autonomy is consistently associated with higher teamwork; communication and lower degree of burnout (Rafferty et al., 2005; Adebayo \& Ezeanya, 2010); and positively related to contextual performance (Gellatly \& Irving, 2001). Respect for professional autonomy means allowing professionals to have substantial control over professional practice, including significant room for exercise of their judgment (MacDonald, 2002). Breaugh (1999) defined autonomy as "the degree to which the job provides substantial freedom, independence, and discretion to the individual in scheduling the work and in determining the procedures to be used in carrying it out". Professional work autonomy is a multidimensional concept, including the three concepts of: work method autonomy (i.e., the degree of discretion/choice nurses have regarding the procedures/methods they utilize in going about their work); work scheduling autonomy (i.e., the extent to which nurses feel they can control the scheduling/sequencing/timing of their work activities); and work criteria autonomy (i.e., the degree to which nurses have the ability to modify or choose the criteria used for evaluating their performance) (Breaugh, 1999). In general, ICU nurses make one care decision every 30 seconds and approximately nine important patient-care decisions per hour, suggesting that exercising judgment is a core nursing activity and influences the quality of care provided (Bucknall, 2000).

Globally, dysfunctional nurse-physician communication is linked to medication errors, patient injuries, and deaths (Kohn et al., 2000). Previous ICU studies have identified several factors associated with the development of burnout: personal characteristics, working conditions, particularly in the 
form of long-term overload, and conflicts, poor communication, little support and no feeling of useful work (Poncet et al., 2007). It is only recently that nursing has been concerned about lack of job autonomy, when hospitals began to lose nurses to other health care settings where they have more involvement in decision making and information sharing (Classens et al., 2004). Professional autonomy is able to moderate burnout (Maslach et al., 2001). The IOM (2010) stated that nurses should be full partners, with physicians and other health care professionals, in redesigning health care. In Egypt, few studies have been done on health care professionals involved in the care of ICU patients about interprofessional communication and its relationship with burnout and autonomy; however some studies focused on nurse-physician collaboration and communication perception (ELSayed \& Sleem, 2011; Elithy et al., 2011). To the best author's knowledge, there is no published research on the problem of interprofessional communication in ICUs in Egypt. Therefore, the purpose of this study is to examine the relationship between interprofessional communication and sharing information and nurses' burnout and work autonomy.

\section{Research aim and questions}

The aim of this study was to examine the relationship between interprofessional communication and sharing information and nurses' burnout and work autonomy.

The primary research question for this study was: what is the relationship between interprofessional communication and sharing information and nurses' burnout and work autonomy? The more specific questions that this study aimed to answer were: What is the prevalence of interprofessional communication and sharing information among physicians and nurses in critical care units? What is the relationship between interprofessional communication and sharing information and nurses' burnout? What is the relationship between interprofessional communication and sharing information and work autonomy?

\section{Material and Methods}

\section{Research design}

This is a quantitative cross-sectional correlational research design.

\section{Setting}

The study was conducted at Damanhour National Medical Institute with total bed capacity of 541 beds. It encompasses all critical care units, namely: general intensive care unit $(\mathrm{N}=21$ beds $)$; coronary care unit $(\mathrm{N}=8$ beds); and emergency recovery unit $(\mathrm{N}=8$ beds). The institute is affiliated to the General Organization for Teaching Hospital and Institutes; and is considered the main teaching hospital in ElBeheira. The facility offers a full range of services including acute inpatient care, intensive care units, hospitalization services; as well as paramedical services.

Subjects

All physicians $(\mathrm{N}=68)$ and all nurses $(\mathrm{N}=99)$, who are working in the previously mentioned units for at least one year experience at Damanhour National Medical Institute, were included $(\mathrm{N}=167)$.

Tool for data collection

The data was collected through self-administered questionnaire comprising four major parts:

\section{Part I}

The Communication and Sharing Information (CSI) scale developed by Anthoine et al. (2014); was used to assess sharing of medical information and the effectiveness of communication between members of the team (physicians, and nurses). It consists of 13items, concerning three subscales, namely: sharing of medical information between healthcare professionals (5-items), communication between physicians and nurses (4-items), and communication between nurses and nurse assistants (4-items). Responses were measured on a 4-point Likert rating scale ranging from (1) never to (4) always. The total score ranged from 13 to 52 . The higher values corresponding to better interprofessional communication and sharing information.

\section{Part II}

The Maslach Burnout Inventory-Human Services Scale (MBI-HSS) developed by Maslach et al., (1996), was used to measure the severity of burnout in the work in order to indicate the frequency with which they experience certain feelings related to their job. It consists of 22-item that measures the three dimensions of burnout: emotional exhaustion ( 9 items), depersonalization (5 items), and lack of personal accomplishment ( 8 items). Responses were measured on a 7-point Likert rating scale ranging from (1) never to (7) every day. The total score ranged from 22 to 154 . All the items that measure emotional exhaustion and depersonalization were scored directly while those of reduced personal accomplishment were scored in a reverse order. Higher scores on emotional exhaustion and depersonalization and lower scores on personal accomplishment indicate burnout, although emotional exhaustion has been identified as the hallmark of burnout; high mean for burnout dimensions are considered when emotional exhaustion $\geq 27$; depersonalization $\geq 14$; and personal accomplishment 0-30 (Maslach et al., 1996).

\section{Part III}

The Global Work Autonomy Scale (GWA) developed by Breaugh (1999), was used to measure 
professional work autonomy. It is a 9-item, with 3 subscales (method, scheduling and criteria). Each subscale consists of three items. Responses were measured on a 7-point Likert rating scale ranging from (1) strongly disagree to (7) strongly agree. The total score ranged from 9 to 63 . The higher the scores, the more being autonomous in the work.

\section{Part IV}

This part included questions related to demographic characteristics of the study subjects such as age, years of experience, and working unit.

\section{Methods}

The study was performed according to the following steps:

Official approval from the hospital administrators of Damanhour National Medical Institute was obtained before the beginning of the research. The study questionnaires were translated into Arabic by the researcher and were tested for content validity by five experts in the field of nursing (for readability; appropriateness; and ease of understanding). Modifications were done accordingly. The tools used in this study were tested for reliability using Cronbach's Alpha Coefficient test, its value was: the Communication and Sharing Information (CSI) scale (0.88); the Maslach Burnout Inventory-Human Services Scale (MBI-HSS) for the 3 subscales ranged from (0.71-0.90); and the Global Work Autonomy Scale (GWA) (0.78). A pilot study was conducted on 7 physicians and 10 staff nurses $(10 \%)$ of the total sample size $(\mathrm{N}=167)$, who were selected randomly from surgical units in order to test the relevance and applicability of the study tool, and who were not included in the main study sample.
3.6 Ethical considerations: The purpose of the study was explained to each physician and staff nurse and oral consent to participate in the study was obtained from them. Confidentiality and anonymity of participants; as well as their right to withdraw from the research at any time were ensured.

Data was collected through self-administered questionnaires that were distributed among the subjects at their working units. Each questionnaire took approximately from 20 to 30 minutes/staff nurse and 10 minutes/physician. The data was collected for a period of 2 months started from the $1^{\text {st }}$ of May 2014 to the $30^{\text {th }}$ of June 2014 .

\subsection{Statistical analysis}

After data collection, it was revised, coded and fed to statistical software SPSS version 17. Continuous variables are presented with mean score with $95 \%$ confidence intervals (CI). The significance level was set at $\mathrm{P}<0.05$. Descriptive statistics were done using frequencies, percentages; mean and standard deviation. Analytical statistics were done using significance test student t-test (used for two sets of data that are significantly different from each other,); One WAY ANOVA (one-way analysis of variance is used to compare means of two or more samples); independent sample t-test (used when two separate sets of independent and identically distributed samples are obtained); and correlations between pairs of continuous variables were calculated using Pearson's correlation coefficients. As for Maslach Burnout Inventory-Human Services Scale (MBIHSS), all subscales scores are considered separate scores and are not to be calculated into a single score; therefore, one score for each subscale.

\section{Results}

Table (1): Demographic characteristics of physicians and nurses working in intensive care units at Damanhour National Medical Institute.

\begin{tabular}{|c|c|c|c|c|}
\hline \multirow{3}{*}{ Demographic Characteristics } & \multicolumn{4}{|c|}{ Profession $(\mathrm{N}=167)$} \\
\hline & \multicolumn{2}{|c|}{ Physicians $(\mathrm{N}=68)$} & \multicolumn{2}{|c|}{ Nurses $(\mathbf{N}=99)$} \\
\hline & No & $\%$ & No & $\%$ \\
\hline \multicolumn{5}{|l|}{ Age (years) } \\
\hline $20-$ & 9 & 13.2 & 14 & 14.1 \\
\hline $30-$ & 35 & 51.5 & 47 & 47.5 \\
\hline $40-60$ & 24 & 35.3 & 38 & 38.4 \\
\hline \multicolumn{5}{|l|}{ Years of experience } \\
\hline$<10$ & 20 & 29.4 & 27 & 27.3 \\
\hline $10-$ & 27 & 39.7 & 36 & 36.4 \\
\hline $20-35$ & 21 & 30.9 & 36 & 36.4 \\
\hline \multicolumn{5}{|l|}{ Working unit } \\
\hline General ICU & 27 & 39.7 & 45 & 45.5 \\
\hline Coronary Care Unit & 25 & 36.8 & 33 & 33.3 \\
\hline Emergency Recovery & 16 & 23.5 & 21 & 21.2 \\
\hline
\end{tabular}


Table (2): Distribution of physicians and nurses in relation to communication and sharing information and nurses' burnout and work autonomy at Damanhour National Medical Institute.

\begin{tabular}{|c|c|c|c|c|c|c|}
\hline \multirow{3}{*}{ Item } & \multirow{3}{*}{ Mean \pm SD } & \multicolumn{4}{|c|}{ Profession $(\mathrm{N}=167)$} & \multirow{3}{*}{$\mathbf{P}$} \\
\hline & & \multicolumn{2}{|c|}{ Physicians $(\mathrm{N}=68)$} & \multicolumn{2}{|c|}{ Nurses $(\mathrm{N}=99)$} & \\
\hline & & Mean & SD & Mean & SD & \\
\hline \multicolumn{7}{|l|}{ Communication and sharing information } \\
\hline Sharing of medical information & $12.8 \pm 1.7$ & 12.9 & 1.2 & 11.2 & 1.7 & 0.975 \\
\hline Nurses-Physicians communication & $11.9 \pm 1.3$ & 12.6 & 1.5 & 10.8 & 2.3 & 0.683 \\
\hline Nurses-Nurse assistants communication & $8.7 \pm 2.1$ & 7.1 & 2.1 & 9.3 & 1.9 & 0.785 \\
\hline Total Communication and sharing information & $34.3 \pm 4.8$ & 34.1 & 4.9 & 31.2 & 3.8 & 0.808 \\
\hline \multicolumn{7}{|l|}{ Burnout } \\
\hline Emotional exhaustion & $36.2 \pm 4.9$ & - & - & 36.2 & 4.9 & - \\
\hline Depersonalization & $18.0 \pm 2.7$ & - & - & 18.0 & 2.7 & - \\
\hline Personal accomplishment & $15.9 \pm 4.8$ & - & - & 15.9 & 4.8 & - \\
\hline \multicolumn{7}{|l|}{ Work Autonomy } \\
\hline Method & $11.4 \pm 2.8$ & - & - & 11.4 & 2.8 & - \\
\hline Scheduling & $12.4 \pm 1.7$ & - & - & 12.4 & 1.7 & - \\
\hline Criteria & $12.8 \pm 2.0$ & - & - & 12.8 & 2.0 & - \\
\hline Total Work Autonomy & $36.6 \pm 4.3$ & - & - & 36.6 & 4.3 & - \\
\hline
\end{tabular}

$P$ : student t-test SD: Standard deviation

Table (3): Relationship between demographic characteristics and total communication and sharing information of physicians and nurses working at Damanhour National Medical Institute.

\begin{tabular}{|c|c|c|c|c|c|}
\hline \multirow{3}{*}{ Demographic characteristics } & \multicolumn{4}{|c|}{$\operatorname{Profession}(\mathrm{N}=167)$} & \multirow{3}{*}{$\mathrm{P}$} \\
\hline & \multicolumn{2}{|c|}{ Physicians(N=68) } & \multicolumn{2}{|c|}{ Nurses(N=99) } & \\
\hline & Mean & SD & Mean & SD & \\
\hline \multicolumn{6}{|l|}{ Age (years) } \\
\hline $20-$ & 36.3 & 1.1 & 31.5 & 4.2 & $0.050^{*}$ \\
\hline $30-$ & 33.7 & 5.6 & 35.1 & 4.1 & 0.853 \\
\hline $40-60$ & 33.9 & 4.6 & 34.4 & 5.6 & 0.934 \\
\hline $\mathbf{P}$ & \multicolumn{2}{|c|}{$0.050 *$} & \multicolumn{2}{|c|}{$0.049 *$} & \\
\hline \multicolumn{6}{|l|}{ Years of experience } \\
\hline$<10$ & 33.9 & 3.9 & 33.3 & 5.0 & 0.957 \\
\hline $10-$ & 34.7 & 5.7 & 35.2 & 3.7 & 0.759 \\
\hline $20-35$ & 33.7 & 4.8 & 34.2 & 5.6 & 0.785 \\
\hline $\mathbf{P}$ & \multicolumn{2}{|c|}{0.746} & \multicolumn{2}{|c|}{0.305} & \\
\hline \multicolumn{6}{|l|}{ Working unit } \\
\hline General ICU & 34.9 & 4.2 & 34.2 & 4.9 & 0.968 \\
\hline Coronary Care Unit & 33.5 & 5.4 & 34.2 & 4.8 & 0.866 \\
\hline Emergency Recovery & 33.9 & 5.4 & 34.8 & 5.0 & 0.879 \\
\hline $\mathbf{P}$ & \multicolumn{2}{|c|}{0.613} & \multicolumn{2}{|c|}{0.901} & \\
\hline
\end{tabular}

P: One WAY ANOVA $\quad P^{\prime}:$ independent sample t-test $\quad * P<0.05$ (significant) 
Table 4: Relationship between demographic characteristics and nurses' burnout and work autonomy at Damanhour National Medical Institute (N=99).

\begin{tabular}{|c|c|c|c|c|c|c|c|c|}
\hline \multirow{3}{*}{$\begin{array}{l}\text { Demographic characteristics } \\
\qquad(\mathrm{N}=99)\end{array}$} & \multicolumn{6}{|c|}{ Nurses' Burnout } & \multirow{2}{*}{\multicolumn{2}{|c|}{$\begin{array}{c}\text { Total } \\
\text { Work } \\
\text { Autonomy }\end{array}$}} \\
\hline & \multicolumn{2}{|c|}{$\begin{array}{l}\text { Emotional } \\
\text { exhaustion }\end{array}$} & \multicolumn{2}{|c|}{ Depersonalization } & \multicolumn{2}{|c|}{$\begin{array}{c}\text { Personal } \\
\text { accomplishment }\end{array}$} & & \\
\hline & Mean & SD & Mean & SD & Mean & SD & Mean & SD \\
\hline \multicolumn{9}{|l|}{ Age (years) } \\
\hline $20-$ & 33.3 & 3.5 & 17.3 & 1.8 & 15.4 & 2.8 & 37.5 & 4.5 \\
\hline $30-$ & 37.2 & 5.1 & 18.7 & 2.9 & 16.4 & 5.3 & 35.7 & 4.0 \\
\hline $40-57$ & 36.1 & 4.7 & 17.4 & 2.4 & 15.5 & 4.8 & 37.3 & 4.5 \\
\hline $\mathbf{P}$ & \multicolumn{2}{|c|}{$0.028^{*}$} & \multicolumn{2}{|c|}{$0.049^{*}$} & \multicolumn{2}{|c|}{0.625} & \multicolumn{2}{|c|}{0.164} \\
\hline \multicolumn{9}{|l|}{ Years of experience } \\
\hline$<10$ & 35.7 & 4.8 & 17.4 & 2.5 & 16.0 & 4.8 & 36.3 & 4.8 \\
\hline $10-$ & 37.3 & 5.4 & 19.0 & 2.8 & 16.1 & 5.0 & 36.0 & 3.5 \\
\hline $20-35$ & 35.6 & 4.4 & 17.5 & 2.4 & 15.7 & 4.8 & 37.4 & 4.6 \\
\hline $\mathbf{P}$ & \multicolumn{2}{|c|}{0.305} & \multicolumn{2}{|c|}{$0.015^{*}$} & \multicolumn{2}{|c|}{0.915} & \multicolumn{2}{|c|}{0.351} \\
\hline \multicolumn{9}{|l|}{ Working unit } \\
\hline General ICU & 35.1 & 5.1 & 18.1 & 2.5 & 15.6 & 4.4 & 36.4 & 4.6 \\
\hline Coronary Care Unit & 36.4 & 4.7 & 18.6 & 2.5 & 15.8 & 4.6 & 37.5 & 4.2 \\
\hline Emergency Recovery & 38.4 & 4.2 & 17.0 & 2.9 & 16.8 & 5.9 & 35.8 & 3.7 \\
\hline $\mathbf{P}$ & \multicolumn{2}{|c|}{$0.035^{*}$} & \multicolumn{2}{|c|}{0.100} & \multicolumn{2}{|c|}{0.626} & \multicolumn{2}{|c|}{0.331} \\
\hline
\end{tabular}

P: One WAY ANOVA

$* P<0.05$ (significant)

Table 5: Correlation matrix between nurses, Communication and sharing information and burnout and work autonomy at Damanhour National Medical Institute (N=99).

\begin{tabular}{|c|c|c|c|c|}
\hline \multirow[b]{2}{*}{ Scale } & \multicolumn{4}{|c|}{ Communication and sharing information } \\
\hline & $\begin{array}{c}\text { Sharing of } \\
\text { medical } \\
\text { information }\end{array}$ & $\begin{array}{l}\text { Nurses-Physicians } \\
\text { communication }\end{array}$ & $\begin{array}{l}\text { Nurses-Nurse } \\
\text { assistants } \\
\text { communication }\end{array}$ & $\begin{array}{c}\text { Total } \\
\text { communication } \\
\text { and sharing } \\
\text { information }\end{array}$ \\
\hline \multicolumn{5}{|l|}{ Burnout } \\
\hline $\begin{array}{l}\text { Emotional } \\
\text { exhaustion }\end{array}$ & $0.40 *$ & $0.32 *$ & $0.35^{*}$ & $0.39 *$ \\
\hline Depersonalization & $0.45^{*}$ & $0.25^{*}$ & $0.39 *$ & $0.40^{*}$ \\
\hline $\begin{array}{l}\text { Personal } \\
\text { accomplishment }\end{array}$ & 0.09 & 0.04 & 0.18 & 0.12 \\
\hline \multicolumn{5}{|l|}{ Work Autonomy } \\
\hline Method & 0.16 & $-0.19^{*}$ & $0.28 *$ & 0.13 \\
\hline Scheduling & -0.05 & -0.09 & 0.04 & -0.02 \\
\hline Criteria & $0.46^{*}$ & $0.31 *$ & $0.47 *$ & $0.45^{*}$ \\
\hline $\begin{array}{l}\text { Total Work } \\
\text { Autonomy }\end{array}$ & $0.30 *$ & -0.02 & $0.41 *$ & $0.28 *$ \\
\hline
\end{tabular}

*: significant correlation $(P<0.05)$

Interpretation of correlation coefficient :Weak (0.1-0.24)

Intermediate (0.25-0.74) Strong (0.75-0.99)

Table (1) : illustrates that the majority of physicians and nurses had from 30 to less than 40 years old (51.5 $\%, 47.5 \%)$, respectively; while the minority had from 20 to less than 30 years old $(13.2 \%, 14.1 \%)$, consecutively. Above one third of physicians had from 10 to less than 20 years of experience. Whereas, nurses got the same percentages for the years of experience from 10 to less than 20 years and from 20 to 35 years $(36.4 \%)$. The majority of physicians and nurses worked at general Intensive Care Unit (ICU) (39.7\%, $45.5 \%)$, respectively.

Table (2) : indicates that there was no significant difference between physicians and nurses in relation to communication and sharing information. The total 
communication and sharing information had a mean $(\bar{X})$ and standard deviation (SD) $(34.3 \pm 4.8)$. The highest communication subscales were: sharing of medical information and nurses-physicians communication which got approximately the same mean and SD $(12.8 \pm 1.7 ; 11.9 \pm 1.3)$, respectively. Whereas, nurses-nurse assistants communication was the lowest subscale $(8.7 \pm 2.1)$. The first dimension of burnout was emotional exhaustion (36.2 \pm 4.9); compared to the last one personal accomplishment $(15.9 \pm 4.8)$. Total work autonomy had a mean and SD (36.6 \pm 4.3$)$. The work autonomy subscales criteria and scheduling got approximately the same mean and SD $(12.8 \pm 2.0 ; 12.4 \pm 1.7)$, consecutively. However, method was the lowest $(11.4 \pm 2.8)$.

Table (3) : reveals that there was a significant difference between physicians and nurses, who had from 20 to less than 30 years old, at communication and sharing information $(\mathrm{P}=0.050)$. Moreover, significant differences were found between age and both physicians and nurses $(\mathrm{P}=0.050,0.049)$, respectively. However, no significant differences were found between years of experience and working unit and both profession.

According to Table (4) : there was a significant difference between age and both nurses' burnout dimensions (emotional exhaustion) and (depersonalization) where $(\mathrm{P}=0.028,0.049)$, respectively. A significant difference was found between years of experience and nurses' burnout (depersonalization) $\quad(\mathrm{P}=0.015)$ Moreover, a significant difference was found between working unit and nurses' burnout (emotional exhaustion) $(\mathrm{P}=0.035)$. On the other hand, no significant differences were found between all demographic characteristics and both nurses' burnout (personal accomplishment) and total work autonomy.

Table (5) : indicates the correlations among nurses' communication and sharing information and both nurses' burnout and work autonomy. An intermediate positive correlation was found between total communication and sharing information and both burnout dimensions: emotional exhaustion and depersonalization and total work autonomy and work autonomy subscale (criteria) $(\mathrm{P}=0.39,0.40,0.28$, 0.45), respectively. Additionally, intermediate positive correlation was found between sharing of medical information, nurses-physicians communication, nurses-nurse assistants communication and both burnout dimensions: emotional exhaustion and depersonalization and work autonomy subscale (criteria) $(\mathrm{P}=0.40,0.32,0.35$; $0.45,0.25,0.39 ; 0.46,0.31,0.47)$, consecutively. Furthermore, a positive intermediate correlation exist between sharing of medical information, and nursesnurse assistants communication and total work autonomy $(\mathrm{P}=0.30,0.41)$, respectively. Moreover, a positive intermediate correlation exist between nurses-nurse assistants communication, and work autonomy subscale (method) $(\mathrm{P}=0.28)$. On the other hand, a negative weak correlation was found between nurses-physicians communication and work autonomy subscale (method) $(\mathrm{P}=-0.19)$. However, no significant correlations were found between total communication and sharing information and its subscales and both burnout dimension (lack personal accomplishment) and work autonomy subscale (scheduling); also no significant correlation was found between nurses-physicians communication and total work autonomy.

\section{Discussion}

Critical care environments are emotionally charged; end-of-life decisions occur frequently, must be made quickly, and can be stressful to healthcare teams (Alameddine et al., 2009). Nurse-physician communication is particularly important, given the interdependence of the two professions and the primary role they play in safe, quality patient care (Robinson et al., 2010). Traditionally, physicians have been the dominant members of healthcare teams, which are true in many countries, including the U.S. where nurses have been seen as subordinates (Dimitriadou et al., 2008). Perhaps, this is due to the "captain of the ship" role physicians have traditionally held where they have been ultimately responsible for patients' outcomes and seen as being "at the helm" (Tabby, 2009). Nurses placed a higher value on nurse-physician communication than physicians (Hojat et al., 2003), and nurses perceiving less physician respect for nurse input and collaboration than physicians (Rosenstein, 2002). Professional autonomy is necessary for implementing nursing standards and guidelines and assuring quality care for those whom nursing serves (American Nurses Association, 2001).

In the present study, there is no significant difference was found between physicians and nurses in relation to communication and sharing information. Moreover, physicians had higher mean than nurses in relation to interprofessional communication and sharing information. This may be due to physicians and nurses perceptions that communication should be respectful and based on an authentic understanding of what one brings to the situation. In addition, true collaboration in ICUs would be possible as physicians understand what nurses could contribute to problem solving or clinical decision making. This is congruent with Thomas et al., (2003), who revealed that physicians were found to have a more positive view than nurses for their perceptions 
regarding nurse-physician communication. On the other hand, Pecukonis et al., (2008) indicated that the profession-centric thinking is a construed and preferred view of the world that is most likely developed and reinforced through health profession education and that health professions are educated in silos, so that they graduate and enter practice not understanding each other's unique perspectives and unable to communicate effectively with each other. Moreover, Robinson et al., (2010) concluded that nurses expressed frustration that physicians did not understand the independent nature of their practice or the scope of their practice and that they expressed disappointment in being purveyors of tasks rather than professionals, which consequently complicates communication in many ways. This was supported by Anthoine et al., (2014), who stated that in hospitals, multiple interactions exist, which in general involve several physicians and nurses as well as different health professionals, that not only requires good communication but also effective coordination of the different actions undertaken and share of medical information, in order to avoid repetition, inconsistency, or incoherence in caring for patients.

Sharing of medical information and nursesphysicians communication were the highest dimensions; followed by nurses-nurse assistants communication dimension. This may be related to the feelings of professional nurses; as well as physicians that they can both understand the common language in relation to patient care; whereas, staff nurses/nurse assistants do not have equal educational qualification level as physicians and professional nurses. In ICUs, nurse assistants are not fully prepared to deal with patients independently as skillful professional nurses who are deeply needed in these settings. Furthermore, sharing of information is essential in ICUs environment in order to exchange the information needed to improve patient care. This is in the same line with Daugherty and Larson (2010), who stated that due to the close proximity to patients, nurses are offered an advantage in assessing their wellbeing and the ability to communicate those changes to the team for improved patient outcomes. Moreover, Anthoine et al., (2014) indicated that the sharing of medical information within the healthcare team ensures the quality of information delivered to the patient. This is partially in accordance with Sirota (2008), who found that nurses were dissatisfied with their overall relationships with physicians and they doubted that physicians understood nursing responsibilities; and they belief that physicians are more likely to respect and appreciate nurses' knowledge and skills when they work closely with nurses and get to know them as in ICUs.
Pertaining to nurses' burnout, high level of critical care nurses' burnout was revealed for the three burnout dimensions: emotional exhaustion; depersonalization; and personal accomplishment. This may be contributed to the work overload in the critical care units, due to staff shortage, decrease resources and increase occupancy rate. Nurses also are confronted with critical situation needed rapid and effective decisions; as well as the nature of these units that are psychologically exhausting for nurses because the increase in mortality rate and rapid deteriorating effects on patients that lead to stress and eventually burnout. This is in line with Maslach et al., (2001), who stated that the elemental quality and the most palpable manifestation of burnout is exhaustion; and that of the three aspects of burnout, exhaustion is the most widely reported and the most thoroughly analyzed, because feelings of exhaustion or job detachment or when helping people toward whom one is indifferent, in turn, lead to a feeling of inefficacy; and lose a sense of accomplishment. They also emphasized that work situation with chronic, overwhelming demands would contribute to exhaustion or depersonalization that is likely to erode one's sense of effectiveness. Furthermore, Guntupalli et al., (2014) revealed that physicians as well as nurses, who work in intensive care units, are influenced by higher levels of professional burnout because of their stressful work demands associated with caring for critically ill patients.

In addition to that, Biaggi et al., (2003) stated that approximately half of residents and nurses from Swiss teaching hospitals met the critical values for emotional exhaustion. In a recent survey performed in French intensivists (interns, residents, attending physicians, and nurses), Embriaco et al., (2007) mentioned that a high level of burnout was identified in almost half of the respondents; and that a low level of personal accomplishment (this subscale has an inverse relationship to burnout) was found in above one third of them. This is partially congruent with Guntupalli et al., (2014), who found that ICU staff had higher emotional exhaustion scores, lower depersonalization scores yet similar personal achievement scores when compared to surgical residents and burnout rate when compared to Chinese nurses (Lei et al., 2010). On the other hand, health care team are especially susceptible to burnout because of their exposure to patient problems (psychological, social, and physical), which leaves them vulnerable to chronic stress, which can be emotionally draining and, in due course, lead to burnout that can have grave implications not only for health care personnel, but also for their patients (Akroyd et al., 2002). This is supported by Alameddine et al., (2009), who found that the 
emotional wellbeing of ICU staff is critical in this complex work environment, and approaches to alleviate stress and emotional exhaustion should be exerted.

Pertaining to work autonomy, the critical care nurses have a high degree of total work autonomy; as well as its three subscales criteria; scheduling; and method work autonomy. This may be due to the critical care nurses are more likely to describe expanding or extending their scope of practice beyond usual nursing procedures and responsibilities, such as specialized clinical competencies related to new technologies and procedures; and decision of organizing their daily work activities. Nurses working in critical care units seem more interested in pushing nursing practice into domains currently within the purview of medicine because of the level of acuity of their patients; therefore they gain independency and are self-managed. They are also independent during their work and are self-managed because of the shortage noted in these units especially during evening and night shifts. This is congruent with Maylone et al., (2011), who mentioned in their studies that the majority of intensive care nurses got high scores for professional autonomy. Moreover, Stewart et al., (2004) investigated professional work autonomy of nurses, and emphasized the importance of their input into the clients care plans as an essential indicator of autonomy; and that their sense of autonomy (e.g. mutual respect and recognition of the relationships in health care teams) was said to be diminished when their nursing knowledge was ignored. McCloskey (1990) also found that autonomy was requirement for nurses' job contentment. Similarly, Myrayyan (2003) showed that nurses' autonomy can be influenced by factors, such as the use of nursing data sets, and the way in organizing their patients' work. Additionally, Fletcher (2001) found that intensive care nurses who perceived that they had greater control over their practice environment, reasonable work demands, and a supportive environment tended to have more satisfaction, performance, autonomy and morale. This is supported by Ryan and Deci (2000), who viewed work autonomy as innate needs that must be met in organizations to promote wellbeing, motivation and performance of staff.

On the other hand, Finn (2001) indicated that nurses are more restricted by their hierarchical, bureaucratic work environment, which leads to decreased expectations of autonomy. Furthermore, Sumner \& Townsend (2003). stated that the work setting influence nurses' autonomy, as they encounter a work environment where patient-care ratios, staff mix, and staffing policies provide instant barriers to their professional survival and therefore, autonomy cannot be achieved when nurses are constantly placed in subordinate roles in the hierarchical structure of hospitals. In addition to that, fewer nurses in the clinical setting and decreased nurse-to-nurse interaction have resulted in feelings of isolation for nurse with decreased opportunities to share ideas and ask questions related to clients' issues and decisions; therefore, less autonomous status (Trossman, 2002). Finally, Stewart et al., (2004) revealed that nurses reported experiencing diminished autonomy when they believed that their contribution to patient care goals was unrecognized, not trusted and unvalued by physicians and colleagues; and added that nurses felt responsible to some extent for coordinating and monitoring the interventions of all disciplines.

Regarding interprofessional communication and sharing information and demographic characteristics, a significant difference was found at the age group from 20 to less than 30 years old between physicians and nurses; as well as between age groups and both physicians (from 20 to less than 30 years old) and nurses (from 30 to less than 40 years old). However, no significant differences were found between years of experience and working unit and both profession. This may be related to the younger physicians, who need to get involved in the work, so that they communicate and share information to get cooperation from the health care team members. Whereas, the middle age nurses are better communicator as they become more involved in the work; constitute the large number of nurses; and have an increase in confidence in their professional role and responsibilities as a nurse. This is congruent with Sirota (2008), who stated that over half of nurses indicated that they had better working relationships and communication with younger physicians than older ones. This is partially in accordance with researchers who have included the physicians' perspective have found that physician age, gender, culture, years of experience and length of time in role may affect nurse-physician work relationships (Sterchi, 2007). On the other hand, Manojlovich and Antonakos (2008) stated that nurses were satisfied in their communication with more experienced physicians than with less experienced. Moreover, Corser, (2000) found that the number of years of experience in ICU was inversely related to communication in view of the often contentious relationship between nurses and physicians. Additionally, Baggs et al., (1997) found that communication significantly varied by type of ICU, and interestingly, nurses in the surgical ICU reported lower levels of satisfaction with communication than did nurses in the medical ICU or general ICU.

According to nurses' burnout and demographic characteristics, nurses, who had 30 to less than 40 
years old, differ significantly than the other age groups for both nurses' burnout dimensions (emotional exhaustion) and (depersonalization). Moreover, nurses who had from 10 to less than 20 years of experience, differ significantly for the nurses' burnout (depersonalization). As for working units, emergency recovery was the highest unit for nurses' burnout (emotional exhaustion). On the other hand, no significant differences were found between all demographic characteristics and nurses' burnout (personal accomplishment). This may be due to the middle aged nurses, are the most reliable and confident person to deal with the patients than novice or older nurses; therefore they are confronted with work related demands and stressors over time. Middle experienced nurses feel impersonal to the patients; in order to overcome the work stress due to the increase in their workload. Despite that emergency recovery unit is a general ICU, nurses feel emotionally exhausted due to the acuity and severity of cases. This is in line with Koivula et al., (2000), who examined burnout among the nursing staff and indicated that burnout increases with age; as well as, nurses with limited work experience had lower levels of burnout.

This is partially congruent with Maslach et al., (2001), who viewed that personal characteristics of the respondent, such as younger age; and participation in an ICU working group were independently associated with severe burnout. Furthermore, in a French study evaluating 2497 nurses working in 165 different ICUs, it was found that four groups of nurses have high burnout syndrome: younger age; participation in ICU work groups; quality of working relationships and end of life related factors (Poncet et al., 2007). On the other hand, Guntupalli et al., (2014) indicated that nurses in ICUs, who are younger in age, are more prone to severe burnout. Ilhan et al., (2008) also found in their study that years of experience had no effect on nurses' burnout. Additionally, an inverse relationship between age and burnout, particularly emotional exhaustion, has been reported; as well as less experienced nurses reported higher burnout (Rupert \& Kent, 2007). Moreover, Embriaco et al., (2007) did not identify age as an independent associated factor of presenting a high level of burnout.

This present study revealed the absence of significant differences between total work autonomy and all demographic characteristics. This may be related to the abilities of critical care nurses to control their practice; and to choose the most suitable method to perform the work, regardless of their age, years of experience and working units, with gratefulness for the nurse manager support. The behavior of less experienced, younger nurses might demonstrate willingness to learn, and wanting to advance in their career compared to more experienced and older nurses in the profession, who have settled into their career. This is not in line with Gillis et al., (2004), who found that, early in their career, nurses were more autonomous in their practice. Moreover, Claessens et al., (2004) found that nurses, with a moderate number of years of work experience (11 to 20 years), had autonomy in scheduling their work and some decision making scope in their practice. Additionally, Denton (2001) found that most experienced group of nurses appeared to have choice or autonomy in the procedures or methods; they use (method) and had a moderating influence on the relationship between the professional work autonomy (criteria) and morale.

An intermediate positive correlation was found between total communication and sharing information and its three subscales and both burnout dimensions: emotional exhaustion and depersonalization. However, no significant correlations were found between total communication and sharing information and its three subscales and burnout dimension (personal accomplishment). This may be contributed to the type of working units, because these ICUs are characterized by bad prognosis/outcomes, high mortality rate, which impact the nurses' work even with interprofessional communication and sharing of medical information; therefore, leading to their feelings of decrease energy, exhaustion and impersonal response toward patients. Despite that ICU nurses are skillful in their work and have good interprofessional communication, the critical state of patients with complications makes them negatively evaluate their performance and feel that they are incompetent. This is in accordance with Rosenstein (2002), who found that nurses' morale and burnout was strongly influenced by their daily interactions with physicians. Nelson et al., (2008) also indicated that nurses who work closely with physicians and participate in shared decision making experience less burnout. Moreover, intensive communication between nurses and physicians may help nurses feel that the work they do is valued and escape from feelings of guilt (Yaguchi et al., 2005). Additionally, Robinson et al., (2003) found that effective health care team communication was linked to decrease nurses' burnout and that nurses experienced higher levels of depersonalization and decreased personal accomplishment, which can be enhanced by working a good schedule, good relationships with co-workers, believing that the patients are improving, and feeling competent in the job. Maslach et al., (2001) also stated that severe burnout was associated with quality of working 
relationships, such as relationship with head nurses and physicians.

This is contradictory with Guntupalli et al., (2014), who revealed that the consequences associated with professional burnout affect both the health care professionals and recipients, who can experience poor communication of healthcare providers as a result of the healthcare professional's burnout. Furthermore, Nelson and Venhaus (2005) found that relationships between nurses and physicians have been recognized as a source of workplace stress because nurses, physicians, and other clinicians, are trained to communicate differently, which makes teamwork in high-stress environments even more challenging. In addition to that, Embriaco et al., (2007) reported that poor relationships between critical care staff contributed to higher level of burnout, which can be decreased through improvements in communication among ICU nurses and physicians which is considered as a protective factor. McMurray et al., (2000) also indicated that relationships between nurses and doctors have been identified as stressors in critical care physicians and nurses for a long time. This was supported by Lautrette et al., (2007), who concluded that in recent years, considerable effort has been expanded to improve communication, and share discussions and decisions in the ICU.

An intermediate positive correlation was found between total communication and sharing information with its three subscales and work autonomy subscale (criteria); as well as, between total communication and sharing information and both sharing of medical information, and nursesnurse assistants communication subscales and total work autonomy. This same correlation existed between nurses-nurse assistants communication and work autonomy subscale (method). On the other hand, a negative weak correlation was found between nurses-physicians communication and work autonomy subscale (method). However, no significant correlations were found between total communication and sharing information and its subscales and work autonomy subscale (scheduling); and between nurses-physicians communication and total work autonomy. This may be contributed to the ICU nurses' feelings as they experience some control over their practice due to the acuity of cases and their longer stay with the patients compared to physicians. The physicians and managers take into consideration the nature and type of this stressful work environment; so they communicate effectively and share medical information with them; thus give them a sense of independency when making decisions about the needed work. Moreover, physicians in these units chose the methods and procedures to be performed, then explain it to nurses due to their beliefs that they are more knowledgeable, when they cannot communicate effectively with nurses; whereas, professional nurses communicate effectively with nurse assistants to tell them which methods to perform. This is in line with Rafferty et al., (2001) found that higher teamwork were positively related to higher levels of professional work autonomy, which is revealed in nurses who were more involved in decision making and who valued input into decision making which is reflective of a component of professional work autonomy (criteria).

Furthermore, Ajeigbe et al., (2013), who demonstrated in their study, that staff in the emergency who used interdisciplinary teamwork, perceived effective communication and sharing of information; they were also more engaged in the functioning of their unit; they have freedom to make decisions regarding patient care without interference from their management staff; and lack of intrusion which, consequently, increased the perceptions of autonomy. Moreover, DiMeglio et al., (2005) showed that implementation of a communication strategy was associated with improved perceptions of autonomy. Nurses, in ICUs, indicated increased autonomy and support from their managers in decision making (Laschinger et al., 2000); as well, its link to work relationships, particularly nursephysician relationships, which involve shared responsibilities (Upenieks, 2003). Additionally, Stewart et al., (2004) revealed that nurses reported experiencing diminished autonomy when communication was difficult. This was supported by D'Amour et al., (2008), who stated that interprofessional communication requires interdependent as opposed to autonomous practice and decision-making based on the premise that health professionals want to work together to provide optimal patient care; therefore, the interdisciplinary health care team is more autonomous with members better integrated.

Finally, the American Nurses Association (2001) stated that one of the essentials for nursing is interprofessional communication and collaboration for improving patient health outcomes. Raiger (2005) argues that communication and respect can ameliorate burnout in nurses. In order to create a healthcare environment with decreased sentinel events, it is important that the nurse and the physician become partners and establish a communication strategy; therefore, radical transformation of professional communication and teamwork is urgently needed (IOM, 2011). The professional practice environment is enhanced through elements as teamwork, effective communication, supportive 
management, and autonomy (Alameddine et al., 2009). Recent guidelines for enhancing teamwork in health care recommend supporting precise and accurate communication through a closed-loop communication protocol, which means ensuring that information sent, was received and interpreted correctly (Salas et al., 2008).

\section{Conclusion}

The current study findings concluded that communication and sharing information was positively correlated with burnout subscales: emotional exhaustion and depersonalization; and work autonomy subscale (criteria). Total communication and sharing information had positive correlation with total work autonomy. Nursesphysicians communication was negatively correlated with work autonomy subscale (method). On the other hand, communication and sharing information had no correlation with burnout subscale (personal accomplishment) and work autonomy subscale (scheduling); and also nurses-physicians communication was not correlated with total work autonomy.

\section{Recommendations}

In light of the findings of the present study, it is recommended that:

- Hospital administrators should implement strategies to create an organizational context that fosters patient-centered communication through:

- unit-based advanced practice nurses to manage interdisciplinary teams;

- development of nurses to enhance competency that is required to empower autonomy;

- nurse-to-nurse coalitions to increase the centrality of nonproductive nurse-physician conflict; and

- enhance daily behaviors that are reflective of equal valuing of all professionals' contributions to patient care.

- Hospital administrators should develop policies and procedures to equalize power dynamics; and guidelines for enhancing teamwork in health care through a closed-loop communication protocol, which means ensuring that information sent was received and interpreted correctly.

- Hospital administrators and nurses should apply interventions to enhance interprofessional communication and reduce burnout, such as:

- ICU research groups;

- stress management workshops;

- periodic job rotation and training in communication; and

- $\quad$ stress management evaluation for nurses.
- Hospital administrators should conduct orientation programs for healthcare team to understand their roles as members of the healthcare team, as well as the roles of coworkers from other disciplines, in order to function effectively as part of a cohesive team.

- The faculties of nursing should:

- focus on communication skills and teamwork and not just on individual technical skills; and

- implement interprofessional education models and interventions to foster communication and collaboration between professions.

- Nurses should apply individual strategies to prevent burnout, such as: training on: stress inoculation, relaxation techniques, time management, assertiveness training, interpersonal and social skills, teambuilding and teamwork.

- Further researches include relationship between interprofessional communication and sharing information and work environment.

\section{Acknowledgments}

The author would like to thank all health care professionals (physicians, and nurses) who participated in the study from Damanhour National Medical Institute.

\section{References}

1. Ackerman, A., (1993): Retention of critical care staff. Crit Care Med, 21(9 Suppl): S394-S395.

2. Adebayo, S., \& Ezeanya, I., (2010): Effects of job autonomy, task identity and profession among health workers in Jos, Nigeria. European Journal of Social Sciences, 14 (1): 116-124.

3. Aiken, L., Clarke, S., Sloane, D., \& et al., (2002): Hospital nurse staffing and patient mortality, nurse burnout, and job dissatisfaction. JAMA, 288: 1987-1993.

4. Ajeigbe, D., McNeese-Smith, D., Leach, L., \& Phillips, L., (2013): Nurse-Physician Teamwork in the Emergency Department: Impact on Perceptions of Job Environment, Autonomy, and Control Over Practice. JONA, 43(3): 142-148.

5. Akroyd, D., Caison, A., \& Adams, R., (2002); Patterns of burnout among U.S. radiographers. Radiologic Technology, 73: 215-223.

6. Alameddine, M., Dainty, K., Deber, R., \& Sibbald, W., (2009): The intensive care unit work environment: Current challenges and recommendations for the future [Electronic Version]. Journal of Critical Care, 24: 243-248.

7. American Nurses Association (ANA). (2001): Code of ethics for nurses with interpretive statements. Silver Springs, MD: ANA. 
8. Anthoine, E., Delmas, C., Coutherut, J., \& Moret, L., (2014): Development and psychometric testing of a scale assessing the sharing of medical information and interprofessional communication: the CSI scale. BMC Health Services Research, 14: 126132. doi: 10.1186/1472-6963-14-126

9. Arnedt, J., Owens, J., Crouch, M., \& et al., (2005): Neurobehavioral performance of residents after heavy night call vs. after alcohol ingestion. JAMA, 294: 1025-1033.

10. Azimi, H., Ashktorab, T., Bagheri, M., \& Bagherzadeh, R., (2011): Experience of Professional Communication among Nurses Working in Educational Hospitals: A Phenomenological Study. J Maz and Univ Med Sci., 21(85): 108-125.

11. Baggs, J., Schmitt, M., Mushlin, A., Eldredge, D., Oakes, D., \& Hutson A., (1997): Nursephysician collaboration and satisfaction with the decision-making process in three critical care units. Am J Crit Care, 6: 393-399.

12. Baggs, J., Schmitt, M., Mushlin, A., \& et al., (1999): Association between nurse-physician collaboration and patient outcomes in three intensive care units. Crit Care Med., 27(9): 19911998.

13. Biaggi, P., Peter, S., \& Ulich, E., (2003): Stressors, emotional exhaustion and aversion to patients in residents and chief residents - what can be done? Swiss Med Wkly, 133: 339-346.

14. Breaugh, J., (1999): Further investigation of the work autonomy scales: two studies. Journal of Business and Psychology, 13(3): 358-373.

15. Bridges, D., (2011): Inter professional collaboration: three best practice models of Inter professional education. Medical Education Online, 16: 6035-6041. DOI: 10.3402/meo.v16i0.6035.

16. Bucknall, T., (2000): Critical care nurses' decision-making activities in the natural clinical setting. J Clin Nurs., 9(1): 25-35.

17. Chitty, K., \& Black, B., (2007): Professional nursing: concepts \& challenges. New York: WB Saunders Co.

18. Classens, B., Van Eerde, W., Rutte, C., \& Roe, R., (2004): Planning behavior and perceived control of time at work. Journal of Organizational Behavior, 25: 937-950.

19. Corser, W., (2000): The contemporary nursephysician relationship: insights from scholars outside the two professions. Nurs Outlook, 48: 263-268.

20. Curtis, J., \& Vincent, J., (2010): Ethics and end-of-life care for adults in the intensive care unit. Lancet, 376: 1347-53. [PubMed: 20934213]

21. D’Amour, D., Goulet, L., Labadie, J., San Martin Rodriguez, L., \& Pineault, R., (2008): A model and typology of collaboration between professionals in healthcare organizations. BMC Health Services Research, 8: 188-202.

22. Denton, W., (2001): Tenure as a moderator of the relationship between autonomy and satisfaction. Applied Human Research Management, 6(2): 105-114.

23. DiMeglio, K., Padula, C., Piatek, C., \& et al., (2005): Group cohesion and nurse satisfaction: examination of a team-building approach. J Nurs Adm., 35(3): 110-120.

24. Dimitriadou, A., Lavdaniti, M., Theofanidis, D., Psychogiou, M., Minasidou, Eu., Konstadinidou-Straukar, A., \& SapountziKrepia, D., (2008): Interprofessional collaboration and collaboration among nursing staff members in Northern Greece. International Journal of Caring Sciences, 1: 140-146.

25. Doran, D., Sidani, S., Keatings, M., \& Doidge, D., (2002): An empirical test of the Nursing Role Effectiveness Model. J Adv Nurs., 38(1): 29-39.

26. Dougherty, M.B. \& Larson, E. (2010): The Nurse-Nurse Collaboration Scale [Electronic Version]. Journal of Nursing Administration, 40(1): 17-25.

27. Elithy, A., Harmina, M., \& Elbialy, G., (2011): Nurses and Physicians Perceptions of Their Interprofessional Relationships at Alexandria Main University Hospital. Journal of American Science, 7(12): 750-757. ISSN: 15451003

28. EL Sayed, K., \& Sleem, W., (2011): Nurse physician collaboration: A comparative study of the attitudes of nurses and physicians at Mansoura University Hospital. Life Science Journal, 8(2): 140-146.

29. Embriaco, N., Papazian, L., Kentish-Barnes, N., Pochard, F., \& Azoulay, E., (2007): Burnout syndrome among critical care healthcare workers [Electronic Version]. Current Opinion in Critical Care, 13: 482-488.

30. Finn, C., (2001): Autonomy: An important component for nurses' job satisfaction. International Journal of Nursing Studies, 38(3): 349-57.

31. Fletcher, C., (2001): Hospital RNs Job Satisfactions and Dissatisfactions. Journal of Nursing Administration, 31(6): 324-331.

32. Gellatly, I., \& Irving, P., (2001): Personality, autonomy, and contextual performance of managers. Human Relations, 14(3): 231-241. 
33. Gillis, A., Jackson, W., \& Beiswanger, D., (2004): University Nurse Graduates: Perspectives on Factor of Retention and Mobility. Canadian Journal of Nursing Leadership, 17(1): 97-112.

34. Greenfield, L., (1999): Doctors and nurses: a troubled partnership. Ann Surg., 230(3): 279288.

35. Guntupalli, K., Wachtel, S., Mallampalli, A., \& Surani, S., (2014): Burnout in the intensive care unit professionals. Indian Journal of Critical Care Medicine, 18(3): 139-143. DOI: 10.4103/0972-5229.128703

36. Hojat, M., Gonnella, J., Nasca, T., Fields, S., Cicchetti, A., Lo Scalzo, A., \& et al. (2003): Comparisons of American, Israeli, Italian and Mexican physicians and nurses on the total and factor scores of the Jefferson scale of attitudes toward physician-nurse collaborative relationships. International Journal of Nursing Studies, 40(4): 427-435.

37. Hough, C., \& Curtis, J., (2005): Long-term sequelae of critical illness: memories and healthrelated quality of life. Crit Care, 9: 145-6. [PubMed: 15774066]

38. Ilhan, M., Durukan, E., Taner, E., Maral, I., \& Bumin, M., (2008): Burnout and its correlates among nursing staff: Questionnaire survey. J Adv Nurs., 61: 100-106.

39. Institute of Medicine of the National Academies, (2010): The future of nursing: Leading change, advancing health. Available at: http://www.nap.edu. Accessed June 8, 2012.

40. Institute of Medicine (IOM). (2011): Accreditation quality report. Available at: http://www.umcelpaso.org/WebShell/umcep.nsf/ TJC\% 20Public \%20Report.pdf. Accessed June 8, 2012.

41. Keenan, G., Cooke, R., \& Hillis, S., (1998): Norms and nurse management of conflicts: keys to understanding nurse-physician collaboration. Res. Nurs. Health, 21: 59-72.

42. Kenaszchuk, C., Reeves, S., Nicholas, D., \& Zwarenstein, M., (2010): Validity and reliability of a multiple-group measurement scale for interprofessional collaboration. BMC health services research, 10: 83-94. Doi:10.1186/14726963-10-83.

43. Kohn, L., Corrigan, J., \& Donaldson, M., eds. (2000): To err is human: building a safer health system. Washington, DC: Institute of Medicine, Committee on Quality of Health Care in America.

44. Koivula, M., Paunonen, M., \& Laippala, P., (2000): Burnout among nursing staff in two
Finnish hospitals. Journal of Nursing Management, 8(3): 149-158.

45. Krogstad, U., Hofoss, D., \& Hjortdahl, P., (2004): Doctor and nurse perception of interprofessional co-operation in hospitals. Int. J. Qual. Health Care, 16: 491-497.

46. Lachinger, H., Finegan, J., Shamian, J., \& Casier, S., (2000). Organizational trust and empowerment in restructured healthcare settings: Effects on staff nurse commitment. Journal of Nursing Administration, 30(9): 413-425.

47. Lautrette, A., Darmon, M., Megarbane, B., \& et al., (2007): A communication strategy and brochure for relatives of patients dying in the ICU. N. Engl. J. Med., 356: 469-478.

48. Lei, W., Youn Hee, K., \& Dong, W., (2010): A review of research and strategies for burnout among Chinese nurses. Br. J. Nurs., 19: 844-50.

49. MacDonald, C., (2002). Nurse autonomy as relational. Nursing Ethics, 9(2): 194-201. doi: 10.1191/0969733002ne498oa

50. Manojlovich, M., \& Antonakos, C., (2008): Satisfaction of Intensive Care Unit Nurses With Nurse-Physician Communication. JONA, 38(5): 237-243.

51. Maslach, C., Jackson, S., \& Leiter, M., (1996): Maslach Burnout Inventory Manual. Palo Alto: Consulting Psychologists Press.

52. Maslach, C., Schaufeli, W., \& Leiter, M., (2001): Job Burnout, Annual Review of Psychology, 53: 397-422.

53. Maylone, M., Ranieri, L., Griffin, M., McNulty, R., \& Fitzpatrick, J., (2011): Collaboration and autonomy: Perceptions among nurse practitioners. Journal of the American Academy of Nurse Practitioners, 23: 51-57. doi: 10.1111/j. 1745-7599.2010.00576.x

54. McCloskey, J., (1990): Two requirements for job contentment: Autonomy and social integration. Journal of Nursing Scholarship, 22(3): 140-144.

55. McMurray, J., Linzer, M., Konrad, T., \& et al., (2000): The work lives of women physicians results from the physician work life study. The SGIM Career Satisfaction Study Group. J. Gen. Intern. Med., 15: 372-380.

56. Merlani, P., Verdon, M., Businger, A., \& et al., (2011): Burnout in ICU caregivers: a multicenter study of factors associated to centers. American Journal of Respiratory and Critical Care Medicine, 184(10): 1140-1146.

57. Mrayyan, M., (2003): Nurse autonomy, nurse job satisfaction and client satisfaction with nursing care: Their place in nursing data sets. Canadian Journal of Nursing Leadership, 16(2): 74-85. 
58. Myhren, H., Ekeberg, Ø., \& Stokland, O., (2013): Job Satisfaction and Burnout among Intensive Care Unit Nurses and Physicians. Critical Care Research and Practice, Article ID 786176. http://dx.doi.org/10.1155/2013/786176

59. Nelson, J., \& Venhaus, R., (2005): Improving Retention through Nurse/Physician Communication [Electronic Version]. Nurse Leader, 3: 54-56.

60. Nelson, G., King, M., \& Brodine, S., (2008): Nurse-physician collaboration on medicalsurgical units. MEDSURG Nursing, Í 7(1): 3540.

61. Orchard, C., Curran, V., \& Kabene, S., (2005): Creating a Culture for Interdisciplinary Collaborative Professional Practice. Online: Medical Education, 10.

62. Pecukonis, E., Doyle, O., \& Bliss, D., (2008). Reducing barriers to interprofessional training: Promoting interprofessional cultural competence. Journal of Interprofessional Care, 22(4): $417-$ 428.

63. Poncet, M., Toullic, P., Papazian, L., \& et al., (2007): "Burnout syndrome in critical care nursing staff," American Journal of Respiratory and Critical Care Medicine, 175(7): 698-704.

64. Rafferty, A., Ball, J., \& Aiken, L., (2001): Are teamworkand professional work autonomy compatible, and do they result in improved hospital care? Quality in Health Care, 10: 32-37.

65. Rafferty, A., Ball, J., \& Aiken, L., (2005): Are teamwork and professional autonomy compatible, and do they result in improved hospital care? Quality in Health Care, 10(Supp. I): 32-37.

66. Raiger, J., (2005): Applying a cultural lens to the concept of burnout. Journal of Transcultural Nursing, 16(7): 71-76.

67. Raj, V., (2006): Occupational stress and radiography. Radiologic Technology, 78: 113122.

68. Robinson, J., Clements, K., \& Land, C., (2003): Workplace stress among psychiatric nurses [Electronic version]. Journal of Psychosocial and Mental Health Services Nursing, 41(4): 32-41.

69. Robinson, F., Gorman, G., Slimmer, L., \& Yudkowsky, R., (2010): Perceptions of Effective and Ineffective Nurse-Physician Communication in Hospitals. Nursing Forum, 45(3): 206-216.

70. Rose, L., (2011): Interprofessional collaboration in the ICU: how to define? Nursing in Critical Care, 16(1): 5-10.
71. Rosenstein, A., (2002): Nurse-physician relationships: impact on nurse satisfaction and retention. Am. J. Nurs., 102: 26-34.

72. Rupert, P., \& Kent, J., (2007): Gender and work setting differences in career-sustaining behaviors and burnout among professional psychologists. Professional Psychology: Research and Practice, 38(1): 88-96.

73. Ryan, R., \& Deci, E., (2000): Selfdetermination theory and facilitation of intrinsic motivation, social development, and well-being. American Psychologist, 55(1): 68-78.

74. Salas, E., Wilson, K., Murphy, C., King, H., \& Salisbury, M., (2008): Communicating, coordinating, and cooperating when lives depend on it: Tips for teamwork. The Joint Commission Journal of Quality and Patient Safety, 34(6): 333-341.

75. Scott, R., Sibon, N., \& Merrick, Z., (2008): The doctor-nurse game in the age of inter professional care a view from Canada. Nursing inquiry, 15(1): 1-2.

76. Sirota, T., (2008): Nurse/physician relationships survey report. Nursing, 38(7): 28-31.

77. Sterchi, L., (2007): Perceptions that affect physician-nurse collaboration in the perioperative setting. AORN Journal, 55(1): 4557.

78. Stewart, J., Stansfield, K., \& Tapp, D., (2004): Clinical nurses' understanding of autonomy: Accomplishing patient goals through interdependent practice. Journal of Nursing Administration, 34(10): 443-450.

79. Sumner, J., \& Townsend, R., (2003): Why are nurses leaving nursing? Nursing Administration Quarterly, 27(2): 164-171.

80. Tabby, D., (2009): Where is the "captain of the ship"? The Journal of American Osteopathic Association, 7: 386-387.

81. The Joint Commission. (2006): Sentinel Event Statistics. Available at: http://www.jointcommission.org/NR/rdonlyres/F A465646-5F5F-4543-AC8F-

E8AF6571E372/0/rootcausese.jpg. Accessed November 30, 2013.

82. The Joint Commission. (2012): Sentinel event data: Root causes by event type. Available at: http://www.jointcommission.org/assets/1/18/Roo t_Causes_Event_ Accessed November 30, 2013.

83. Thomas, E., Sexton, J., \& Helmreich, R., (2003): Discrepant attitudes about teamwork among critical care nurses and physicians. Critical Care Medicine, 31(3): 956-959.

84. Thompson, D., \& Stewart, S., (2007). Handmaiden or right-hand man: Is the 
relationship between doctors and nurses still therapeutic. International Journal of Cardiology, 118: 139-140.

85. Trossman, S., (2002): Satisfaction guaranteed? A sampling of strategies to keep experienced nurses on the job. American Nurse, 34(3): 12-14.

86. Tyson, P., \& Pongruengphant, R., (2004): Five-year follow-up study of stress among nurses in public and private hospitals in Thailand. International Journal of Nursing Studies, 41: 247-254.

87. Upenieks, V., (2003): The interrelationships of organizational characteristics of magnet hospitals, nursing leadership, and nursing job satisfaction. The Health Care Manager, 22(2): 83-98.

88. Wall, R., Curtis, J., Cooke, C., \& Engelberg, R., (2007): Family satisfaction in the ICU: differences between families of survivors and nonsurvivors. Chest, 132: 1425-33. [PubMed: 17573519]

89. Yaguchi, A., Truog, R., Curtis, J., \& et al., (2005): International differences in end-of-life attitudes in the intensive care unit: results of a survey. Arch. Intern. Med., 165: 1970-1975. 